\title{
Data Sharing: a New Editorial Initiative from the International Committee of Medical Journal Editors. Implications for the Editors' Network
}

\author{
Fernando Alfonso, MD, and on behalf of the Editors' Network European Society of Cardiology Task Force* \\ Chairman Editor's Network, Department of Cardiology, Hospital Universitario de La Princesa, Instituto de Investigación sanitaria IIS-IP, Universidad Autónoma de Madrid, \\ Madrid, Spain
}

The International Committee of Medical Journal Editors (ICMJE) provides recommendations to improve the editorial standards and scientific quality of biomedical journals. These recommendations range from uniform technical requirements to more complex and elusive editorial issues including ethical aspects of the scientific process. Recently, registration of clinical trials, conflicts of interest disclosure, and new criteria for authorship -emphasizing the importance of responsibility and accountability-, have been proposed. This year a new editorial initiative to foster sharing of clinical trial data has been launched. This review discusses this novel initiative with the aim of increasing awareness among readers, investigators, authors and Editors of the Editors' Network of the European Society of Cardiology. (Korean Circ J 2017;47(3):307-313)

KEY WORDS: Editorial ethics; Scientific process; Data sharing; Clinical trial; Trial registration; Authorship; Conflict of interest; Big-data; Scientific Journals.

The Editors' Network of the European Society of Cardiology (ESC) is committed to promote the implementation of high-quality editorial standards among ESC National Societies Cardiovascular Journals (NSCJ). ${ }^{1-4)}$ NSCJ play a major role in disseminating highquality scientific research. However, they also play a relevant role in education and harmonization of clinical practice. ${ }^{3)}$ Most NSCJ are published in local languages but many have English editions and have gained international scientific recognition. ${ }^{1-4)}$ NSCJ nicely complement ESC official journals and, altogether, provide an effective means to disseminate European cardiovascular research. In a globalized and highly competitive editorial environment, promoting high quality editorial standards remain of paramount importance to increase the scientific prestige of NSCJ.1-4) From its conception the Editors' Network strongly advocated for the adherence to the uniform recommendations of the International Committee of Medical Journal Editors (ICMJE)."1 In the mission statement document the Editors' Network committed to adapt NSCJ to follow these general editorial recommendations." However, NSCJ are highly heterogeneous in scope and contents and these new recommendations should be embraced progressively, considering currently existing editorial policies and the editorial freedom of the NSCJ.1-4)

Ethical issues play a growing role in ensuring the credibility of the scientific process. ${ }^{5-13)}$ Biomedical research relies on trust. However, transparency also represents a major tenet in the scientific process. ${ }^{5-8)}$ This review will discuss the new editorial recommendations on data sharing issued by the ICMJE. ${ }^{14)}$ Novel ICMJE recommendations always appear as provocative, and often as too ambitious, when initially presented. Moreover, implementation of editorial changes is rather demanding from a technical and logistic point of view. Adherence to novel editorial initiatives is challenging not only for editors but also for the entire

Received: October 5, 2016 / Accepted: December 20, 2016

Correspondence: Fernando Alfonso, MD, Chairman Editor's Network, Department of Cardiology, Hospital Universitario de La Princesa, Instituto de Investigación sanitaria IIS-IP, Universidad Autónoma de Madrid, C/ Diego de León 62, Madrid 28006, Spain

E-mail:falf@hotmail.com

* Co-authors' information is available at the end of the article.

* This article is a joint simultaneous publication initiative involving all interested National and Affiliated Cardiovascular Journals of the European Society of Cardiology.

- The authors have no financial conflicts of interest.

This is an Open Access article distributed under the terms of the Creative Commons Attribution Non-Commercial License (http://creativecommons.org/ licenses/bync/3.0) which permits unrestricted non-commercial use, distribution, and reproduction in any medium, provided the original work is properly cited. 
scientific community. Therefore, many Editors have a natural tendency to avoid stepping ahead as early adopters of new "editorial experiments" and usually prefer keep moving in their comfort zone until the "sea change" has matured. ${ }^{1-4)}$ However, experience has thought us that all editorial initiatives developed by the ICMJE eventually prevail playing a critical role to maintain the credibility of the scientific process. ${ }^{9-13)}$ Highly successful recent examples include trial registration, conflicts of interest initiative and the new requirements for authorship. ${ }^{9-13)}$

The novel ICMJE recommendations on data sharing ${ }^{14)}$ are discussed herein from a didactic perspective with the aim to provide new editorial insights and hopefully to be progressively adopted and implemented by the NSCJ.

\section{Sharing Clinical Trial Data: The New ICMJE Proposal}

The ICMJE considers that there is a moral obligation to responsible share the data generated by clinical trials. ${ }^{14)}$ The rationale underlying this global endeavor is that patients have assumed a risk by accepting to participate in a trial. Accordingly, making the obtained data publicly available represents a responsible initiative to facilitate the advancement of science. Sharing the data would increase trust in the conclusions reach by trials. Indeed, data sharing allows confirmation of the results by independent researches. ${ }^{14)}$ Furthermore, new hypothesis may be pursuit by different groups of investigators. This initiative may foster leveraging data to answer different research questions or scientific inquiries not contemplated in the original study. If science becomes an open process many researchers would benefit of taking advantage of reliable data generated somewhere else. Therefore, data sharing emerges as the best way to ensure that all the information gathered by trials is made freely and widely available, so that it can be readily used to advance scientific knowledge. ${ }^{14)}$ The use of previously collected data to further advance science is difficult to be criticized. As discussed, this honours the volunteerism of the patients who signed up and consented to participate in a trial.

Governments, funding agencies, scientific societies, the industry and even the lay society growingly demand sharing clinical trial data. Therefore, the ICMJE suggests that editors should help to meet this ethical obligation by devising new editorial policies specifically addressing this issue. ${ }^{14)}$

The first consideration is to clarify what is exactly a clinical trial. According to the ICMJE definition, a clinical trial is a study that prospectively assigns people to an intervention in order to assess the cause-and-effect relationship between that intervention and the ensuing health outcome.5)

The ICMJE considers that sharing "de-identified" individual patient data should become part of the publication process of clinical trials. ${ }^{14)}$ This strategy protects patient's confidentiality rights. The requirement, however, is restricted to the individualpatient data underpinning the results presented in the published article. Importantly, a clear plan for data sharing should be disclosed at the time of initial trial registration and should be also presented at the time of manuscript submission. The proposal requires clinical trialists to declare that they will share their data publically as a prerequisite for publishing the trial. ${ }^{14)}$ They should compromise to freely release individual patient raw data at the time they submit the manuscript for consideration.

It is important to keep in mind that clinical trial registration was a previous ICMJE editorial initiative aimed to address problems related to publication bias (selective publication of positive trials), endpoints inconsistency and redundant research.910) Potentially, public repositories provide an optimal means not only for initial trial registration but also for individual-patient data sharing. From now on the plan for data-sharing would be an important step of the clinical trial registration initiative. ${ }^{910) 14)}$ Details on whether the data would be freely available upon request, or only after a formal application, that eventually will be approved after an agreement is reached on data use conditions, should be presented. Finally, it has been proposed that the data should be made public no more than 6 months after publication of the original study in the journal.910)14) Clinicaltrials.com, a widely used non-for profit scientific repository, ${ }^{910)}$ has already adapted its registration platform to specifically clarify data-sharing plans at the time of clinical trial registration.

Proponents of "open science" will be pleased by this new requirement for sharing clinical trial data. ${ }^{14)}$ Obviously, this editorial initiative may have profound consequences on the planning, conduction and reporting of clinical trials and, in fact, may deeply influence research and publication strategies. ${ }^{14)} \mathrm{As}$ a result, the idea is to implement this requirement for any clinical trial that begins to enroll patients 1 year after the official adoption of this editorial policy by the corresponding journal. ${ }^{14)}$ The initiative will also have major implications for the editorial process. Indeed, Editors are supposed to monitor the data sharing process and, eventually, address potential irregularities. These might include requests of clarification to the authors, notification to academic institutions, publication of expressions or concern or even retractions.

Finally, the ICJME acknowledges that the rights of the investigators and sponsors should be protected. ${ }^{14)}$ Moreover, credit to the original report should be granted by including a unique 
identifier of the data set. It is emphasized that credit should be always given to the original investigators that posted the data after publication of their research. Furthermore, additional investigators using these databases should request collaboration of the original investigators that originally collected the data to ensure adequate data interpretation, management and analysis.

\section{Pending Issues on Data Sharing}

Although it appears clear that this initiative will further improve transparency and the overall integrity of the scientific literature, some remaining issues need to be addressed. There are inherent resistance to embrace open science initiatives from some academic institutions or investigators that defend the idea of exploiting their "own" data. ${ }^{15116)}$ Until now clinical researchers were discouraged from working with clinical trial data they did not generate themselves. ${ }^{15) 16)}$ Likewise, trialists tended to see trial data as their personal property and would routinely refuse requests for data sharing. In fact, until recently most researchers and pharmaceutical industry groups were opposed to making raw data available after trial publication. This practice, however, differs from other disciplines (as genomics or economics) where data sharing is common place. ${ }^{1516)}$

Obtaining reliable, high-quality original data requires a major research effort. A sufficient period of time from the time of article publication to the need to share the raw data should be allowed to give original investigators the possibility of publishing additional subgroup analyses from their own data. ${ }^{14)}$ This new proposal will further increase the pressure on academic investigators that frequently have not the required resources to publish their subsequent analyses and require time to prepare the new the manuscripts. ${ }^{14)}$ Notably, most researchers have no experience with the process of releasing or dealing with public data. Furthermore, the effort and resources required to organize the raw data in a way that would be comprehensible to others investigators remain a cause of major concern. ${ }^{14)}$

Data-access to non-trial researches may disclose problems not recognized by the initial investigators. Although this will increase transparency and, therefore, trust in trial results, it might also generate confusion and undue scientific controversies. It is difficult to envision how the new researches will gain the required detailed knowledge of the complicated datasets enjoyed by the original trial investigators..$^{14)} \mathrm{A}$ reliable assessment of the data requires a deep knowledge on the study background and to be able to properly address many nuances and practical considerations. These include precise information on the way variables were defined, how data was collected and how results were finally coded and entered into the database. The initiative might be fraught with problems related to incorrect analysis resulting in inaccurate results and erroneous interpretations, potentially damaging science. ${ }^{14)}$

Finally, Editors, already deluged with work, will need to check that all of the raw data of the published articles has been eventually released as promised. Different results may emerge from misconceptions regarding what data should be analysed to answer specific questions. ${ }^{14)}$ If there are differences in results, it will be difficult to decide which analysis provides the most accurate reflection of the data. This could generate an undue "scientific noise", with contradictory results and rectifications, which may generate confusion and frustration in the scientific community. Finally, this may also promote the simultaneous publication in several journals of conflicting results from the same database by different groups. ${ }^{14)}$

As many issues should be still clarified the ICMJE asked for feedback on its preliminary editorial proposal on clinical trial data sharing before April 18, 2016. ${ }^{14)}$ Obviously, the initiative will only gain the required maturity from the experience gained during its adoption and implementation.

\section{Previous Initiatives on Data Sharing}

Several leading academic entities have been previously working on this field. The British Medical Journal pioneered an editorial initiative of data sharing. ${ }^{17)}$ In 2012 this policy took effect only for trials on drug and devices but, in 2015, the requirement of data sharing "on request" was extended to all submitted clinical trials. ${ }^{17)}$

Some have proposed that individual patient data may also be of major value during the "peer review" process by permitting independent verification of the results before final publication. ${ }^{18)}$ Although this initiative might be of potential value most reviewers are already deluged with work and this extra task could generate fatigue and burn out phenomena. In addition, many good clinical reviewers do not have the expertise required to manage data and to perform confirmatory statistical analyses. ${ }^{18)}$ Some journals, as JAMA, previously developed some related initiatives including the request for independent statistical analyses by an academic statistician of industry-sponsored trials. ${ }^{19)}$

The World Health Organization (WHO) and the Institute of Medicine (IOM) also announced important declarations on clinical trial transparency. The IOM issued specific guidelines for trial data sharing. ${ }^{20)}$ WHO initially presented a statement on public disclosure 
of clinical trial results and, subsequently, encouraged sharing of research datasets whenever appropriate. ${ }^{21-23)}$ More recently, the WHO developed global norms for sharing data and results during public health emergencies, with special focus on clinical, epidemiologic, and genetic features of new infectious diseases and experimental therapeutics and vaccines. In emergency situations, data need to be shared quickly before the information is published. ${ }^{23)}$

The National Health, Lung and Blood Institute (NHLBI) also developed detailed data-sharing practices allowing public access to trial raw data and a data repository currently including over half a million patients from over 100 trials and observational studies. ${ }^{24)}$ In 2015 the NHLBI discussed its intent to make public digital data from its funded trials. ${ }^{24)}$

\section{Platforms and Repositories}

Up to 30000 clinical trials are conducted annually worldwide generating a huge volume of patient-level raw data. ${ }^{25}$ Currently, however, available portals for data sharing are still not adequate. Most of them require a time consuming request, including a detailed research proposal with the study design, main endpoints and a statistical plan. ${ }^{25}$ The submitted proposal is then reviewed by an independent research panel that decides whether to approve the request for data. ${ }^{25)}$ Currently, this process takes too long. When eventually the data is obtained oftentimes it is not readily usable. For instance, variable names may be not informative and long annotation files need to be carefully revised. ${ }^{25)}$

The requirement of elaborating a detailed research proposal to request data access ensure an adequate review process. ${ }^{2126)}$ However, the means to facilitate data sharing from the data holder to the researcher may be cumbersome and challenging to implement. Some systems provide an electronic form or template. ${ }^{21)}$ However, when these are not available a de novo proposal should be generated outlining the purpose, the statistical analysis plan, the research team, and potential conflicts of interest. The review process may come from an internal or external review panel selected by the data holder or by a third party. ${ }^{25-27)}$ Finally, data can be shared through a public website or by direct communication between the data holder and the researcher. In most cases, however, controlled access is required. Before any analysis is started reviewing all the accompanying documentation to assist the researcher in the understanding of the original clinical trial and the methodology used, remains critical. Furthermore, the data holder may require a legally binding data sharing agreement and should be available to provide the required support when questions arise. ${ }^{27)}$
Major care should be taken to prevent the perils that may undermine the value of data sharing. ${ }^{14)}$ Data from trials should be responsibly used. ${ }^{28)} A$ recent survey from UK Clinical Trial Units disclosed some potential risks associated with data sharing. ${ }^{29}$ These basically included misused of data, incorrect secondary analyses, resource requirements and identification of patients. ${ }^{29}$ (30) Researches are responsible to present the data in a format amenable for external secondary use. Repositories should be prepared to make raw data available in standardized platforms in a fully comprehensive manner. It is clear that funding is required to help the researches in these tasks. Data sharing from trials with anonymized patient-level data with associated metadata and supporting information should be made available to other researchers following an independent analysis of the research proposals. Developing and adopting a standard approach to protecting patient privacy is urgently required. ${ }^{14)}$

Some academic research organization consortiums focussed on the study of cardiovascular diseases, ${ }^{311}$ have developed interesting tools for data sharing. Presentation of a standardized request in a Web portal is required. Proposals are to be analyzed by a scientific committee, including members designed by the consortium and a statistician along with the trial's principal investigator. The idea is to ensure an adequate use of the data base and correct statistical analyses while averting the problem of multiple investigators proposing the same analyses. ${ }^{311}$

Finally, an adequate infrastructure should be organized to support effective data sharing. In this regard, the role of the industry is significantly growing as demonstrated by some joint initiatives, as the Yale University Open Data (YODA) project.16)32)

\section{Statistical Issues}

Statisticians play a key role in developing data sharing strategies. ${ }^{33)}$ They should be involved from the very beginning to organize the research strategy and the required analytical techniques. ${ }^{33} \mathrm{~A}$ data sharing working group of medical research statisticians, from the pharmaceutical and biotechnological industry and from the academia, has recently addressed the challenges of accessing research data for re-analyses. In this scenario statisticians should move from their classical role as "gate-keepers" of data to that of "data facilitators". ${ }^{33)}$ Specific techniques are required to ensure adequate data manipulation in order to convert the data that was collected and entered in the data base into data that is analytically usable. Converting row data in standardized formats may be challenging. Moreover, familiarity with the required statistical 
programing language is necessary. Independent statisticians should play a major role in guiding the principles of re-analysis based on the researchers' request while, at the same time, guarding against misleading conclusions. They should be fully aware that additional analyses may yield different results compared with the original analyses. Accordingly, they should be prepared to face criticism but, at the same time, they should be able to openly challenge previous statistical methods. ${ }^{33)}$

Statistical guidance may be required for appropriate interpretation of results from re-analyses where different methods have been utilized. In particular, it is important to keep in mind the inherent risk of over-interpretation the results from multiple subgroup analyses. ${ }^{34}$

Likewise, documents for best practices in data anonymization have been developed. ${ }^{35)}$ Statisticians should be familiar with this methodology. Risk to patient privacy can be mitigated by data reduction techniques. Data holders are responsible for generating de-identified datasets to offer protection for patient privacy through masking or generalization of main identifiers. In addition, legally binding data sharing agreements should include a compromise not to attempt to identify patients. ${ }^{35)}$ In particular, it is recommended that data use agreements are signed by data holder and researchers. Only appropriately qualified "named" researchers should be granted access to the data. Finally, high security levels should be implemented for data transferring. Resources, costs and effort required to make patient-level data available for third party research may be considerable and, therefore, adequate funding should be organized. ${ }^{35}$

\section{Credit to Original Authors}

A clear motivation for researches to conduct randomized clinical trials is the opportunity to publish different studies in addition to the main study with the primary endpoint. These secondary analyses may be of major value to unravel new findings from the original dataset. ${ }^{36-37)}$ Many have proposed that the time to open the process of data sharing should be extended to 2 years, or even to 5 years in selected complex or large studies. This will allow a precious time for the original investigators to further scrutinize and analyze in depth their own data. In addition, mechanisms are required to ensure that the external analyses are conducted adequately and not merely to undermine the original findings. As blinding is necessary during trial execution once the study is completed the research teams concentrates in publishing the primary findings as soon as possible. Following this, usually there is a series of pre- planned additional analyses. These studies may be organized by collaborative teams with investigators from different institutions with relatively poor support. Secondary analyses are also very important for co-investigators and junior scientists. To respect this legitimate interest an extension from the 6 month-period after the primary data has been published should be warranted. ${ }^{36-37)}$

Credit should be granted to the original researchers that create data sets that other investigators find useful. ${ }^{14) 15}$ The academia rewards scientists with recognition for making their discoveries public. Original investigators may be tempted to consider "research parasites" those performing secondary analyses of their data. Direct collaboration between primary and secondary researches is, therefore, necessary to ensure proper data analysis and interpretation. Collaboration with original data gatherers is strongly recommended. ${ }^{1415)}$ The original investigators that designed and conducted the trial and obtained sources of founding deserve receiving the adequate scientific credit. ${ }^{28)}$ There is a need to financially compensate original investigators for their efforts and the cost of making trial data available. ${ }^{36) 37)}$

\section{Conclusion}

The data transparency revolution is here to stay. This is just another step ahead into a culture of open science and it is clear that we are at the dawn of a new age. ${ }^{38 / 39}$ Challenges and hurdles in adoption and implementation of the new ICMJE recommendation will be progressively overcome. ${ }^{40)}$ Experience gained by leading journals will eventually allow a balanced compromise between the interests of the original researchers and that of the scientific community as a whole. NSCJ should progressively adapt their policies to increase awareness of the importance of data sharing and promote policies designed to enhance transparency in biomedical research.

\section{Acknowledgements}

We are grateful for the support and assistance of Ismahem Ouertani and Michael Alexander from the ESC National Cardiac Societies Relations Department and the Publication Department at the Heart House.

\section{References}

1. Alfonso F, Ambrosio G, Pinto FJ, et al. European National Society 
Cardiovascular Journals. Background, rationale and mission statement of the "Editors' Club". Rev Esp Cardio/ 2008;61:644-50.

2. Alfonso F, Ambrosio G, Pinto FJ, et al. European Society of Cardiology National Cardiovascular Journals: the 'Editors' Network'. Eur Heart J 2010;31:26-8.

3. Mills $P$, Timmis $A$, Huber $K_{\text {, et }}$ al. The role of European national Journals in Education. Heart 2009;95:e3.

4. Alfonso F. The Editors' Network of the European Society of Cardiology. Eur Heart J 2011;32:919-21.

5. International Committee of Medical Journals Editors. Recommendations for the conduct, reporting, editing, and publication of scholarly work in medical journals. (Updated December 2015) Available: http://www. icmje.org.

6. Council of Science Editors. White Paper on Publication Ethics. CSE's White Paper on Promoting Integrity in Scientific Journal Publications. (Updated 2012) Available: http://www.CouncilScienceEditors.org.

7. World Association of Medical Editors. WAME Professionalism Code of Conduct The new WAME Professionalism Code of Conduct for medical journal editors. Available: http://www.wame.org.

8. Committee On Publication Ethics. COPE. Code of Conduct and Best Practice Guidelines for Journal Editors. Available: http://publicationethics. org/resources/guidelines.

9. De Angelis CD, Drazen JM, Frizelle FA, et al. Is this clinical trial fully registered?--A statement from the International Committee of Medical Journal Editors. N Engl J Med 2005;352:2436-8.

10. Alfonso F, Segovia J, Heras M, Bermejo J. Publication of clinical trials in scientific journals: Editorial issues. Rev Esp Cardio/ 2006;59:1206-14.

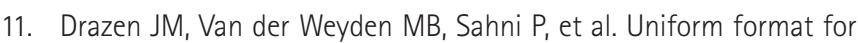
disclosure of competing interests in ICMJE journals. N Engl J Med 2009;361:1896-7.

12. Alfonso F, Timmis A, Pinto FJ, et al. Conflict of interest policies and disclosure requirements among European Society of Cardiology National Cardiovascular Journals. Eur Heart J 2012;33:587-94.

13. Davidoff F, DeAngelis CD, Drazen JM, et al. Sponsorship, authorship, and accountability. N Eng/J Med 2001;345:825-6.

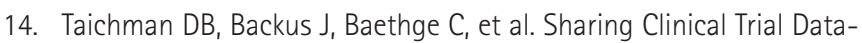
-A Proposal from the International Committee of Medical Journal Editors. N Eng/ J Med 2016;374:384-6.

15. Merson L, Gaye O, Guerin PJ. Avoiding Data Dumpsters--Toward Equitable and Useful Data Sharing. N Engl J Med 2016;374:2414-5.

16. Krumholz HM, Waldstreicher J. The Yale Open Data Access (YODA) Project--A Mechanism for Data Sharing. N Engl J Med 2016;375:403-5.

17. Loder $E$, Groves $T$. The BMJ requires data sharing on request for all trials. BMJ 2015;350:h2373. doi: 10.1136/bmj.h2373.

18. Kavsak PA. The International Committee of Medical Journal Editors proposal for sharing clinical trial data and the possible implications for the peer review process. Ann Trans/ Med 2016;4:115.

19. Manamley N, Mallett S, Sydes MR, et al. Data sharing and the evolving role of statisticians. BMC Med Res Methodol 2016;16(Suppl 1):75.

20. Institute of Medicine. Sharing clinical trial data: maximizing benefits, minimizing risk. Washington, DC: The National Academies Press; 2015.

21. Vallance P, Freeman A, Stewart M. Data Sharing as Part of the Normal Scientific Process: A View from the Pharmaceutical Industry. PLoS Med 2016;13:e1001936.

22. www.who.int/ictrp/results/WHO_Statement_results_reporting_ clinical_trials.pdf?ua $=1$.

23. Modjarrad K, Moorthy VS, Millet P, Gsell P-S, Roth C, Kieny M-P. Developing global norms for sharing data and results during public health emergencies. PLoS Med 2015;13;e1001935.

24. Coady SA, Wagner E. Sharing individual level data from observational studies and clinical trials: a perspective from NHLBI. Trials 2013;14:201.

25. Geifman N, Bollyky J, Bhattacharya S, Butte AJ. Opening clinical trial data: are the voluntary data-sharing portals enough? BMC Med 2015;13:280

26. Van Tuyl S, Whitmire AL. Water, Water, Everywhere: Defining and Assessing Data Sharing in Academia. PLoS One 2016;11:e0147942.

27. Sudlow R, Branson J, Friede T, Morgan D, Whately-Smith C. EFSPI/PSI working group on data sharing: accessing and working with pharmaceutical clinical trial patient level datasets - a primer for academic researchers. BMCMed Res Methodo/ 2016;16(Suppl 1):73.

28. Drazen JM. Data Sharing and the Journal. N Engl J Med 2016;374:e24 doi: 10.1056/NEJMe1601087.

29. Hopkins C, Sydes M, Murray G, et al. UK publicly funded Clinical Trials Units supported a controlled access approach to share individual participant data but highlighted concerns. J Clin Epidemio/ 2016;70:17-25.

30. Lo B. Sharing clinical trial data: maximizing benefits, minimizing risk. JAMA 2015;313:793-4.

31. Ross JS, Krumholz HM. Open Access Platforms for Sharing Clinical Trial Data. JAMA 2016;316:666.

32. Academic Research Organization Consortium for Continuing Evaluation of Scientific Studies--Cardiovascular (ACCESS CV). Sharing Data from Cardiovascular Clinical Trials--A Proposal. N Engl J Med 2016:375:407-9.

33. Fletcher $\mathrm{C}$, Hollis $\mathrm{S}$, Burger HU, Gerlinger C. Statistical guidance for responsible data sharing: an overview. BMC Med Res Methodol 2016;16 (Suppl 1):74.

34. Tucker $\mathrm{K}$, Branson J, Dilleen $\mathrm{M}$, et al. Protecting patient privacy when sharing patient-level data from clinical trials. BMC Med Res Methodol 2016;16 (Suppl 1):77. 
35. International Consortium of Investigators for Fairness in Trial Data Sharing, Devereaux PJ, Guyatt G, Gerstein H, Connolly S, Yusuf S. Toward Fairness in Data Sharing. N Eng/ J Med 2016;375:405-7.

36. Hayes $R$, Ayles H, Binka F, Cowan F, Kamali A, Kapiga S, Kleinschmidt I, Mayaud P, Patel V, Smith P, Weiss H. Sharing clinical trial data. Lancet 2016;387:2287.

37. Strom BL, Buyse M, Hughes J, Knoppers BM. Data sharing, year 1 access to data from industry-sponsored clinical trials. N Engl J Med 2014;371:2052-4.

38. Navar AM, Pencina MJ, Rymer JA, Louzao DM, Peterson ED. Use of open access platforms for clinical trial data. JAMA 2016;315:1283-4

39. Gonçalves LM, Seabra-Gomes R. [Celebrating the 10th anniversary of the Portuguese Cardiology Data Collection Center: a reflexion on its past, present, and future]. Rev Port Cardio/ 2012;31:763-8.

40. Horton R. Offline: Data sharing why editors may have got it wrong. Lancet 2016;388:1143.

\section{Co-authors (Datails)}

Karlen Adamyan, MD', Jean-Yves Artigou, MD², Michael Aschermann, MD³, Michael Boehm, MD4, Alfonso Buendia, MD5, Pao-Hsien Chu, MD ${ }^{6}$, Ariel Cohen, MD , Livio Dei Cas, MD ${ }^{8}$, Mirza Dilic, MD ${ }^{9}$, Anton Doubell, MD ${ }^{10}$, Dario echeverri, MD ${ }^{11}$, Nuray Enç, MD ${ }^{12}$, Ignacio Ferreira-González, MDD ${ }^{13}$, Krzysztof J. Filipiak, MD ${ }^{14}$, Andreas Flammer, MD ${ }^{15}$, Eckart Fleck, MD ${ }^{16}$, Plamen Gatzov, MD ${ }^{17}$, Carmen Ginghina, MD ${ }^{18}$, Lino Goncalves, MD ${ }^{19}$, Habib Haouala, MD20, Mahmoud Hassanein, MD21, Gerd Heusch, MD22, Kurt Huber, MD² ${ }^{23}$ Ivan Huli, MD24, Mario Ivanusa, MD ${ }^{25}$, Rungroj Krittayaphong, MD², ChuPak Lau, MD27, Germanas Marinskis, MD²8, François Mach, MD² ${ }^{29}$, Luiz Felipe Moreira, MD ${ }^{30}$, Tuomo Nieminen, MD¹ , Latifa Oukerraj, MD², Stefan Perings, MD ${ }^{33}$, Luc Pierard, MD ${ }^{34}$, Tatjana Potpara, MD ${ }^{35}$, Walter Reyes-Caorsi, MD ${ }^{36}$, Se-Joong Rim, MD ${ }^{37}$, Olaf Rødevand, MD, Georges Saade, MD ${ }^{39}$, Mikael Sander, MD ${ }^{40}$, Evgeny Shlyakhto, MD ${ }^{41}$, Bilgin Timuralp, MD², Dimitris Tousoulis, MD³, Dilek Ural, MD4, J. J. Piek, MD ${ }^{45}$, Albert Varga, MD ${ }^{46}$, Thomas F. Lüscher, MD ${ }^{47}$, and on behalf of the Editors' Network European Society of Cardiology Task Force
${ }^{1}$ Editor-in-Chief, Armenian Journal of Cardiology, ${ }^{2}$ Editor-in-Chief, Archives des maladies du cœur et des vaisseaux Pratique, ${ }^{3}$ Editor-inChief, Cor et Vasa, ${ }^{4}$ Editor-in-Chief, Clinical Research in Cardiology, ${ }^{5}$ Editor-in-Chief, Archivos de Cardiologia de Mexico, ${ }^{6}$ Editor-in-Chief, Acta Cardiologica Sinica, ${ }^{7}$ Editor-in-Chief, Archives of Cardiovascular Diseases, ${ }^{8}$ Editor-in-Chief, Journal of Cardiovascular Medicine, ${ }^{9}$ Editor-in-Chief, Medicinski Zurnal, ${ }^{10}$ Editor-in-Chief, SA Heart, ${ }^{11}$ Editor-in-Chief, Revista Colombiana de Cardiologia, ${ }^{12}$ Editor-inChief, Kardiyovaskuler Hemsirelik Dergisi, ${ }^{13}$ Editor-in-Chief, Revista Española de Cardiología, ${ }^{14}$ Editor-in-Chief, Kardiologia Polska, ${ }^{15}$ Editor-in-Chief, Cardio News, ${ }^{16}$ Editor-in-Chief, Bulgarian Journal of Cardiology, ${ }^{17}$ Editor-in-Chief, Romanian Journal of Cardiology, ${ }^{18}$ Editor-in-Chief, Revista Portuguesa de Cardiologia, ${ }^{19}$ Editorin-Chief, Revista Guatemalteca de Cardiologia, ${ }^{20}$ Editor-in-Chief, Cardiologie Tunisienne, ${ }^{21}$ Editor-in-Chief, The Egyptian Heart Journal, ${ }^{22}$ Editor-in-Chief, Basic Research in Cardiology, ${ }^{23}$ Editor-in-Chief, Cardiology Letters, ${ }^{24}$ Editor-in-Chief, Cardiologia Croatica, ${ }^{25}$ Editorin-Chief, Thai Heart Journal, ${ }^{26}$ Editor-in-Chief, Thai Heart Journal, ${ }^{27}$ Editor-in-Chief, Journal of the Hong Kong Colleage of Cardiology, ${ }^{28}$ Editor-in-Chief, Seminars in Cardiovascular Medicine, ${ }^{29}$ Editor-inChief, Cardiovascular Medicine, ${ }^{30}$ Editor-in-Chief, Arquivos Brasileiros de Cardiologia, ${ }^{31}$ Editor-in-Chief, Sydänääni (Heart Beat), ${ }^{32}$ Editorin-Chief, La Revue Marocaine de Cardiologie, ${ }^{33}$ Editor-in-Chief, Der Kardiologie, ${ }^{34}$ Editor-in-Chief, Acta Cardiologica, ${ }^{35}$ Editor-in-Chief, Heart and Blood Vessels, ${ }^{36}$ Editor-in-Chief, Revista Uruguaya de Cardiologia, ${ }^{37}$ Editor-in-Chief, Korean Circulation Journal, ${ }^{38}$ Editor-inChief, Hjerteforum, ${ }^{39}$ Editor-in-Chief, Heart News, ${ }^{40}$ Editor-in-Chief, Cardiologisk Forum, ${ }^{41}$ Editor-in-Chief, Russian Journal of Cardiology, ${ }^{42}$ Editor-in-Chief, Anatolian Journal of Cardiology, ${ }^{43}$ Editor-in-Chief, Hellenic Journal of Cardiology, ${ }^{44}$ Editor-in-Chief, Archives of the Turkish Society of Cardiology, ${ }^{45}$ Editor-in-Chief, Netherlands Heart Journal, ${ }^{46}$ Editor-in-Chief, Cardiologia Hungarica, ${ }^{47}$ Editor-in-Chief, European Heart Journal 